\title{
O PENSAR COMPLEXO E O OLHAR FENOMENOLÓGICO DA FORMAÇÃO DOCENTE NA PERSPECTIVA DA DIMENSÃO HUMANA
}

\author{
Enilda Rodrigues de Almeida Bueno ${ }^{1}$ \\ Universidade Federal de Tocantins - UFT. Palmas, Brasil \\ João Henrique Suanno \\ Universidade Estadual de Goiás - UEG. Goiânia, Brasil.
}

\begin{abstract}
Resumo: Esta pesquisa foi desenvolvida durante o estágio pós-doutoral e contou com a análise das contribuições de Husserl (1996), Merleau-Ponty (1999), Bueno (2011, 2014, 2016), Morin (2000, 2001, 2005), Torre (2009), Moraes (2003, 2014), Moraes e Almeida (2012), Santos, J. H. Suanno e M. V. R. Suanno (2013), J. H. Suanno, M. V. R. Suanno e Pinho (2014), entre outras. Seu objetivo foi sistematizar conceitos e princípios dos referenciais destacados, buscando aproximações que contribuam no redimensionamento da educação, especificamente, da formação docente a partir de uma perspectiva do humano e da compreensão existencial no mundo vivido. Nesse sentido, a problemática tem relação com a possibilidade de avançar nas propostas de formação docente pela perspectiva da fenomenologia e da complexidade, com destaque às dimensões humana e inter/transdisciplinar, como contraponto para redimensionar a formação reducionista e técnica, ainda presente no contexto atual. A pesquisa se justifica pela investigação de novas perspectivas epistemológicas e ontológicas para transcender os limites conceituais da formação docente contemporânea. As abordagens investigadas se aproximam em relação à valorização do humano articulada às dimensões inter/transdisciplinar, buscando atender suas especificidades, a partir do mundo real e global.
\end{abstract}

Palavras-chave: Complexidade; Fenomenologia, Formação Docente.

\section{THE COMPLEX THINKING OF AND THE PHENOMENOLOGICAL LOOK AT TEACHING TRAINING WITHIN THE HUMAN DIMENSION PERSPECTIVE}

\begin{abstract}
The present research was developed during the post-doctoral stage departing from an analysis of the contributions made by Husserl (1996), Merleau-Ponty (1999), Bueno (2011, 2014, 2016,), Morin (2000, 2001, 2005), Torre (2009), Moraes (2003, 2014), Moraes and Almeida (2012), Santos, J. H. Suanno and M. V. R. Suanno (2013), J. H. Suanno, M. V. R. Suanno e Pinho (2014), among others. The main objective of this study was to review and deepen concepts and principles found in the works mentioned above, searching for approaches that may contribute to a new agenda for education, especially concerning the training of novice teachers from the point of view of human dimension and of the existential comprehension in the experienced world. In this sense, the discussion relates to the possibility of making progress in the proposals for a teacher training both from the point of view of phenomenology and complexity with an emphasis on the human dimension (in the trans- and interdisciplinary perspectives) as means of countering the reductionist and technical training of teachers, which are often
\end{abstract}

\footnotetext{
1 Pós-doutoranda, bolsista PNPD/CAPES, no Programa de Pós-Graduação Stricto Sensu Interdisciplinar em Educação, Linguagem e Tecnologias - IELT, da Universidade Estadual de Goiás - UEG. Campus de CSEH/Anápolis - GO. (Supervisionada pelo Prof. Dr. João H. Suanno PhD). Contato: enilda.bueno@uft.edu.br.
} 
found nowadays. This piece of research is motivated by the search for epistemological and ontological perspectives, so that one can go beyond the conceptual limits of the contemporary training of teachers. The authors included in the study converge in how they value the human from the trans- and interdisciplinary points of view, while trying to be understanding of human specificities in the factual global world.

Keywords: Complexity; Phenomenology, Teacher Training.

\title{
EL PENSAMIENTO COMPLEJO Y LA MIRADA FENOMENOLOGÍCA DE LA FORMACIÓN DOCENTE BAJO LA PERSPECTIVA DE LA DIMENSIÓN HUMANA
}

\begin{abstract}
Resumen. Esta investigación fue desarrollada durante la etapa posdoctoral a partir del análisis de las contribuciones de Husserl (1996), Merleau-Ponty (1999), Bueno (2011, 2014, 2016), Morin (2000, 2001, 2005), Torre (2009), Moraes (2003, 2014), Moraes y Almeida (2012), Santos, J. H. Suanno y M. V. R. Suanno (2013), J. H. Suanno, M. V. R. Suanno y Pinho (2014), entre otros. Su objetivo fue examinar y profundizar conceptos y principios del marco destacado, buscando aproximaciones que contribuyan para el redimensionamiento de la educación; más específicamente, a la formación docente bajo la perspectiva humana, y de la comprensión existencial del mundo vivido. En ese sentido, la problemática está relacionada con la posibilidad de hacer progresos en las propuestas de formación docente a partir de la fenomenología y la teoría de la complejidad, en especial las dimensiones humana e inter/transdisciplinar, como contrapunto para redimensionar la formación reduccionista y técnica que todavía está presente en el contexto actual. Esta investigación se justifica a partir de la búsqueda de nuevas perspectivas epistemológicas y ontológicas para trascender los límites conceptuales de la formación docente contemporánea. Los enfoques investigados se aproximan con relación a la valorización de lo humano a partir de las dimensiones inter y transdisciplinar, con el objetivo de atender sus especificidades a partir del mundo real y global.
\end{abstract}

Palabras clave: Complejidad, fenomenología, formación del profesorado.

\section{Introdução}

As pesquisas no âmbito educacional e, especificamente, sobre formação docente, têm sido objeto de inúmeras publicações no Brasil e exterior (Nóvoa, 1999, Pineau, 2004, Pukall, Silva e Zwierewicz, 2013, Rodrigues e Schwantz, 2016, entre outros). Os resultados dessas investigações têm indicado a necessidade de continuar investindo em formação inicial e continuada, com o propósito de potencializar inovações na atividade docente e melhorar os processos de ensino e de aprendizagem.

Apesar de toda inovação presente na realidade atual, foi priorizada, especialmente a partir da década de 1990, uma perspectiva de formação docente que se resume ao desenvolvimento de competências técnicas para uma atuação prática restrita, acrítica e aligeirada, direcionada para o atendimento prioritário das demandas do mercado. Esse modelo tem sua base de sustentação na perspectiva neoliberal e, de acordo com Santana (2009), provoca a descaracterização do trabalho do docente.

No Brasil, as argumentações neoliberais passam não somente pela questão financeira e da qualidade dos produtos, mas, também, pelas relações estabelecidas nas atividades educacionais formativas. Nesse sentido, a delimitação da educação como um bem econômico reforça a desigualdade, a exclusão e a desumanização do indivíduo 
(Brenchetti, 1999), acentuadas pela ênfase na formação técnica para o mercado de trabalho.

Essa condição motivou esta pesquisa, cujo objetivo foi sistematizar produções que envolvem a formação docente e apresentam possibilidades para avançar sobre os processos formativos, contribuindo para ultrapassar a visão reducionista, técnica e mercadológica que persiste na realidade atual. Espera-se que seus resultados possam contribuir para elaboração de uma proposta de formação docente na perspectiva sistêmica, inter/transdisciplinar e criativa do fenômeno educacional.

No decorrer da estruturação da educação no contexto nacional e internacional, diversas perspectivas em relação à formação de professores foram constituídas, levando em consideração questões de ordem econômica, social, política, cultural e ideológica de cada período. Ou seja, ao ocorrer mudanças e transformações macrossociais, surgem também novos modos de organizar o processo educacional, bem como novas metodologias para formação de profissionais que atuam nesta esfera. Todas as mudanças que vêm ocorrendo no âmbito educacional, portanto, fazem parte de uma política mais ampla.

Diante do exposto, é inegável que a formação docente exerce uma influência fundamental na qualidade do exercício da prática pedagógica. O que se observa é que a legislação tem apontado, especialmente a partir da Lei de Diretrizes e Bases da Educação Nacional - LDB 9394/96 (Brasil, 1996), para um processo de aligeiramento e de empobrecimento da formação de professores. Tal fato demonstra um trabalho de configurações atreladas a ações como os Parâmetros Curriculares Nacionais, Política do Livro Didático, Diretrizes Curriculares Nacionais para Formação de Professores e o sistema de avaliação de larga escala, que também, na sua maioria, tem como objetivo principal atender o mercado e o capital. Mészáros (2005) faz uma crítica contundente a esse modelo excludente de educação e lança o desafio de uma educação para além do capital.

Nessa linha de pensamento neoliberal, a formação e atuação docente se apresentam restritas e subjugadas por um sistema político mais amplo, desumano e distante do mundo vivido e complexo da sociedade contemporânea. Essa orientação reforça a desigualdade, a exclusão, a competitividade e o individualismo. Enfím, observa-se que há um esquecimento dos princípios provindos da ética, que são fundamentais para o respeito e a dignidade humana, bem como para a constituição de uma educação mais humana, integral e, de fato, solidária.

Esse modelo de formação docente se resume ao desenvolvimento de competências técnicas para uma atuação prática restrita ao que se vai ensinar, provocando uma distorção na formação e atuação docente. Essa problemática tem nos impulsionado à continuidade da pesquisa, em busca de novos referenciais e metodologias que possam contribuir para uma reflexão complexa e transformadora sobre o processo da formação docente no Brasil e exterior.

Partimos dessa inquietação e propomos a seguinte questão norteadora da pesquisa: Como contribuir para avançar nas propostas de formação docente a partir da fenomenologia e da complexidade, com destaque às dimensões humana, criativa, e inter/transdisciplinar, como contraponto para redimensionar a formação reducionista e técnica, ainda presente no contexto atual? Entendemos ser necessário, assim como Suanno (2013), a busca de uma educação que se permita construir na ação e reflexão permanentes dos sujeitos que dela fazem parte, priorizando a integração dos saberes, a autorregulação e a autoprodução de suas ações e conhecimentos. Uma educação que contemple o indivíduo, a sociedade e a natureza, estimulando percepções e ações sistêmicas sobre o local e o global. 
Este estudo se justifica, portanto, pela investigação dos referencias da fenomenologia e da complexidade como fundamentos para contribuir com a formação docente numa sociedade globalizada, que requer do indivíduo ousadia e transformações constantes. Buscou-se, neste estudo, promover um diálogo entre categorias que sustentam os dois referencias, de modo a propiciar uma concepção de conhecimento, que implica incorporação de abordagens teóricas e metodológicas amplas, sistêmicas e que valorizem a complexidade do humano e de seu contexto. Assim como afirmam Freire (2007), Moraes e Suanno (2014) e Zwierewicz (2017), precisamos de abordagens que superem os esquemas estreitos das visões parciais da realidade e se fixem na compreensão da totalidade.

Seguindo esse raciocínio, Moraes e Suanno (2014) propõem o desafio de romper com uma educação que segue a lógica binária, herdada do racionalismo cartesiano, bem como da linearidade de causa e efeito, de certezas absolutas e permanentes e de verdades generalizáveis, ainda presentes na educação de modo geral. Para isso, os autores apresentam a lógica do pensamento complexo, da incerteza, das verdades temporárias, onde o sujeito, em seu contexto e significados, constrói e é construído pelo conhecimento.

Nesse sentido, as contribuições de Merleau-Ponty (1999) são fundamentais ao afirmar que todo saber instala-se nos horizontes abertos pela percepção. O primeiro contato do homem com o mundo é dado, necessariamente, por meio da percepção, cujo sujeito é o corpo. Portanto, não podemos conhecer o mundo sem conhecer o homem e sua complexidade estrutural. Para o autor, o mundo não é o que 'eu penso', mas é aquilo que 'eu vivo'.

No pensamento complexo de Morin (2005), os modelos de pensamento linear são questionados para que se possa ir além, considerando o potencial da aleatoriedade, da incerteza, da imprevisibilidade e da impossibilidade de separação entre sujeito e objeto. Pinto (1992) reforça que, diante do pensar complexo, o homem, a máquina e o ambiente estão intrinsecamente interligados. Nesse sentido, vale lembrar que o raciocínio linear aumenta a produtividade industrial por meio da automação, mas não consegue resolver o problema do desemprego e da exclusão social por ela gerado.

Em contrapartida, a fenomenologia e a complexidade propõem reflexões sobre a existência humana em seus aspectos individual, social e ambiental, possibilitam-nos compreender as microrrelações de poder, nos aproximando de uma dimensão mais ampla e significativa da nossa existência, situando-a nos âmbitos da prática social e educacional. Esse processo tem como condição mobilizadora a ação humana, pois somente o homem é responsável por atribuir sentido e transformar a sua própria realidade. Como afirma Heidegger (1988, p. 44) o ser-no-mundo “.... é um ser para a possibilidade."

De acordo com Husserl (1996 apud Bueno, 2014), para que possamos atingir esse nível de reflexão filosófica, existe a necessidade de romper com o senso comum ou cientificista preso à aparência, quando o 'eu', as 'experiências particulares' e os 'fenômenos em geral' são assumidos como coisas em si. É preciso chegar à atitude fenomenológica, a qual nos leva à raiz dos fenômenos e permite-nos ir à essência do objeto, observando o que ainda não foi visto. Esse processo faz com que o homem alcance a condição de ser-para-si, ou seja, que ao mesmo tempo tenha consciência de si, do outro e do mundo.

Temos, nessa mesma perspectiva, a afirmação de Morin, (2001) de que é necessário substituir um pensamento que está separado por outro que está ligado. Esse reconhecimento exige que a causalidade unilinear seja substituída por outra, circular e sistêmica. E, ainda que a lógica clássica seja corrigida por uma dialógica capaz de 
conceber noções simultaneamente complementares e antagônicas, o conhecimento da integração das partes ao todo é completado pelo reconhecimento do todo no interior das partes.

A fenomenologia e a complexidade estão presentes em várias teorias que têm como fundamento básico as percepções do indivíduo e os significados atribuídos a essas percepções. Assim, a aprendizagem se dá pela percepção e ocorre quando o indivíduo incorpora o conhecimento como seu. Esse conhecimento é capaz de alterar a realidade, oportunizando dimensões novas e transformadoras para o indivíduo, que possibilitam seu desenvolvimento. Nesse processo, o seu campo perceptual é alterado no acúmulo e na dialética resultante de sua cognição, onde teoria e prática fazem parte de um mesmo sistema.

Aprender significa atribuir significados, manipular os significantes e alterar novamente as percepções. A complexidade estabelece a relação entre as partes e a organização do todo e, por meio dessa interconexão, leva à visão de contexto. Nada na realidade está isolado, tudo se apresenta num processo de interconexão.

$\mathrm{O}$ termo complexidade provém de complectere, cuja raiz plectere significa trançar, enlaçar. Em suas obras, Morin tem esclarecido sobre o novo paradigma que envolve uma visão complexa e esclarece,

"Complexus significa o que foi tecido junto; de fato, há complexidade quando os elementos diferentes são inseparáveis constitutivos do todo e ainda quando há um tecido interdependente, interativo e inter-retroativo entre o objeto de conhecimento e seu contexto, as partes e o todo, o todo e as partes, as partes entre si. Por isso, a complexidade é a união entre a unidade e a multiplicidade" (Morin, 2000, p. 38).

A partir da existência em meio a uma realidade complexa em um mundo globalizado, essa perspectiva de pensar o fenômeno educação, pela complexidade, na contemporaneidade, nos remete a Husserl, filósofo e matemático do século XX, quando nos convida a:

"Transcender a mesma narração de fatos históricos para penetrar no sentido interno dos mesmos, na teleologia interna que os orienta. $\mathrm{O}$ pensador recorre à história não como ingênuo compilador de dados ou crítico de documentos, mas como leitor de um passado desde a perspectiva de um presente constituído por seu mundo espiritual. O filósofo busca a verdade interior que escapa ao positivismo historicista: "Pelo fato de conceber ideias, o homem torna-se um homem novo, que, vivendo na finitude, se orienta para o polo do infinito". (1996, p. 52).

No percurso inusitado da reflexão fenomenológica e complexa é necessário “... abandonar nossa visão dogmática, para compreendermos que existem muitos sentidos e reconhecermos que se trata de mais uma visão entre tantas outras possíveis" (Bueno, 2016, p. 76). Essa ideia é importante para análise da realidade sistêmica e estrutural, de forma rigorosa, como requer o pensamento complexo. Além disso, nos remete ao conhecimento multidimensional, do paradigma da complexidade, como possibilidade de superar a fragmentação, a mutilação, a separação.

De acordo com Morin (2010, p. 177), no "... aspirar a multidimensionalidade, o pensamento complexo comporta em seu interior um princípio de incompletude e de incerteza" que nos motiva à busca incessante de sempre querer saber mais da existência complexa vivenciada. E a educação, enquanto processo humano interminável, compreende, ao mesmo tempo, a inseparabilidade da ordem e da desordem, a certeza da incerteza, o previsível do acaso, a parte do todo, o observador do observado, o racional do irracional, o uno do múltiplo. 
As ideias de Husserl e Morin se apresentam adequadas e compatíveis para responder à problemática investigada. A saber, como repensar a formação docente, que se apresenta numa visão reducionista do ser e na fragmentação dos saberes, em prol de uma perspectiva de educação centrada no humano, nas dimensões de inter/transdisciplinaridade, na visão de totalidade sistêmica. Nesse interim, destacamos dimensões e/ou indícios perceptíveis no pensamento dos dois teóricos e que são compreensíveis para um olhar mais sensível e humano sobre a formação docente e a educação no mundo real e atual.

São tais reflexões que tornam esta pesquisa relevante e que são tratadas aqui de forma detalhada a partir de seus precursores. Nesse sentido, buscamos em dois referenciais extremamente elaborados - fenomenologia e complexidade -, perspectivas epistemológicas e ontológicas para transcender os limites conceituais da educação e da formação docente contemporânea.

\section{Método}

Entende-se a metodologia como um caminho do pensamento e a prática exercida na abordagem da realidade. O método, por sua vez, se caracteriza como a alma da teoria, sendo imprescindível no sentido de estabelecer parâmetros para transitar no e pela construção do conhecimento científico.

As pesquisas no âmbito das Ciências Humanas e Sociais utilizam-se, em sua maioria, da abordagem epistemológica no campo qualitativo ou qualitativo/quantitativo, promovendo certo grau de diferenciação em relação às Ciências Naturais, não somente quanto às questões filosóficas da abordagem, como também no perfil do pesquisador, nas técnicas de coleta e no modo de interpretação dos dados.

Para efetivação desta pesquisa foi realizado um levantamento bibliográfico sobre a produção na área de formação de professores, com viés humano fenomenológico e do pensamento complexo, inter/transdisciplinar como suporte teórico para as análises e reflexões. Trata-se, portanto, do uso da abordagem qualitativa-fenomenológica.

No desenvolvimento da pesquisa, priorizou-se a análise da fenomenologia de Edmund Husserl, iniciada no século XIX, assim como a complexidade do pensamento de Edgar Morin, filósofo contemporâneo do século XXI, cujos objetivos são revelar o mistério do homem, do mundo e da razão. Husserl e Morin propõem a superação da visão ingênua, empírica, incompleta, privada da reflexão, que não dá conta da complexidade e subjetividade humana, por uma perspectiva de interações complexas e fenomenológicas como caminhos para ampliar a visão sobre a realidade. Esse processo converge com as pesquisas em Ciências Humanas e Sociais que priorizam uma nova ontologia, permeada por diferentes metodologias, para abarcar a complexidade humana, institucional e planetária no século XXI.

Nesse sentido afirma Moraes (2014, p. 51) "A complexidade requer necessariamente métodos capazes de dialogar com as emergências e as incertezas de compreender a causalidade circular que move os sistemas complexos, de reconhecer a complementaridade presente nos antagonismos e nos paradoxos que, em realidade, tanto enriquecem o pensamento e as construções culturais e sociais."

Consideramos importante, nessa linha, o método da fenomenologia de Husserl que é um movimento teórico, uma postura filosófica com método próprio, que busca sempre o rigor do conhecimento. Propõe descrever o mundo visto pela consciência, em todos os seus aspectos. Nesse sentido, o conhecimento não é concebido como um veredicto, nem um dogma.

Para tanto, a fenomenologia não se prende a um único aspecto da realidade, achando que ele é suficiente para conhecer tudo o que existe. Busca uma leitura 
dialética da realidade, entendendo toda a realidade em todos os seus aspectos: histórico, social, político, sentimental e de vivência do homem.

Nesse processo, a qualidade da pesquisa se constitui na ação de formação do pesquisador no diálogo com as fontes, impulsionando uma trajetória que necessita de tempo e dedicação na busca de respostas para o objeto de pesquisa. Essa perspectiva possibilita ao pesquisador uma postura mais flexível na relação com os dados coletados para análise.

A sistematização desta pesquisa, em forma de uma aproximação simultaneamente histórica e reflexiva de dois referenciais importantes como a fenomenologia e o pensamento complexo, nos convida a um olhar mais amplo, múltiplo, em conjunto, ligando saberes diversos para analisar todos os aspectos dessa realidade e, quiçá, propor mudanças de paradigmas que precisam ser superados.

Repensar a formação docente e a educação contemporânea, nesse processo, pressupõe ultrapassar o que está posto, superar o que aparentemente está determinado, romper com a forma positivista de investigar o objeto com proposições cientificistas e, supostamente, neutras. Pretende-se, com isso, colaborar para pensar o mundo de modo complexo, compreendendo o fenômeno em sua gênese, em todas as dimensões, com análise rigorosa, mas não exata.

\section{Resultados e discussão}

Conforme já enunciado na primeira parte deste artigo, entendemos que os dois referenciais investigados apresentam contribuições significativas para a formação docente. Os dois aportes teóricos se preocupam, efetivamente, com o homem, a educação, o mundo e suas relações no espaço e no tempo, o que nos assegura afirmar que suas ideias se entrelaçam e se complementam.

A partir da perspectiva dos dois referenciais, observa-se a necessidade de superação da visão reducionista da formação docente, para composição de uma nova perspectiva em relação ao objeto de estudo. É um convite à compreensão do processo de formação do homem, a partir do mundo em que se estabelecem as relações individuais, sociais e com o meio ambiente.

As discussões preliminares permitem conceber que as duas abordagens teóricas investigadas se constituem e se sustentam com base em uma visão não linear. Elas se apresentam abertas à incompletude do ser, buscam a essência do objeto, utilizam-se do rigor a partir da realidade vivida e não possuem uma ortodoxia, pois se questionam constantemente. Tais formulações, por conseguinte, produzem mudanças profundas na compreensão de mundo, de educação e, em particular, da formação docente. Dada a compreensão do caráter de interdependência e interatividade existente entre sujeito e objeto, homem e mundo, razão e emoção, resgatam a visão de contexto da realidade, demonstrando que vivemos numa grande rede ou teia de interações complexas e inacabadas.

Podemos dizer, então, que se faz necessário ir além da atitude natural ou dogmática, que só observa a objetividade dada, para que possamos chegar à atitude complexa ou fenomenológica, que parte do questionamento da objetividade e o relaciona a todas as vivências, com a preocupação do rigor necessário, mas sem a pretensão de exatidão. Essa postura nos ajuda, no caso deste estudo, na perspectiva de uma educação humana, inter/transdisciplinar e criativa, a contribuir para efetivação da educação como processo aberto, incerto e capaz de práticas de autoavaliação para rever posições e mudanças. 


\section{Formação docente inter/transdisciplinar}

Vivemos num mundo globalizado, onde a necessidade de novas metodologias de trabalho é emergente, visando a formação de um cidadão consciente, criativo, inovador e protagonista na luta pelas transformações necessárias na sociedade e na educação. A proposta interdisciplinar está presente no referencial fenomenológico e no pensar complexo, pois estes propõem romper com o pensamento linear, superando fragmentações para aproximar os saberes das diferentes áreas do conhecimento e destas com a realidade.

Para Fazenda (2001, p. 17), o “... pensar interdisciplinar... tenta, pois, o diálogo com outras formas de conhecimento, deixando-se interpenetrar por elas... não se ensina, nem se aprende, vive-se, exerce-se." Esse pensar interdisciplinar é proposto por Husserl e Morin quando afirmam que o ser humano está em constante transformação, vivendo e aprendendo, a cada dia, com o novo que se apresenta. Dessa forma, o humano é compreendido como ser aberto e inconcluso, que busca sempre completar-se, embora nunca alcance isso.

Acreditamos que a interdisciplinaridade como prática de vida pode contribuir para mudar o campo educacional, em prol de uma educação ampla, integral, que considere a globalidade e a especificidade de cada sociedade. Para tanto, vale dizer, como o faz Savater (2000, p. 171), que “... a educação tem como objetivo completar a humanidade." Assim, a interdisciplinaridade busca conciliar interesses da convivência humana.

O trabalho interdisciplinar é particularmente complexo e fenomenológico, pois diz respeito às pessoas e ao seu contexto sociocultural e filosófico, aos sujeitos, aos acontecimentos, aos conflitos de liberdade e de decisão, tanto no plano individual quanto no coletivo. Um trabalho interdisciplinar busca contrapor as atividades autoritárias e individualistas que estão presentes nas práticas sociais e também nas educativas, propondo, assim, uma atuação coletiva que se apresente como uma possibilidade de reorganizar nossas atividades, a partir da pessoa e do seu mundo.

De todo modo, o professor precisa tornar-se um profissional com visão integrada da realidade, compreender que um entendimento mais profundo de sua área de formação não é suficiente para dar conta de todo o processo de ensino. Ele precisa apropriar-se também das múltiplas relações conceituais que sua área de formação estabelece com as outras ciências. Nesse sentido, Bastos assinala:

... a ação humana constitui uma unidade que integra práticas, significados pessoais e culturais a elas associados e, certamente, componentes emocionais e afetivos. O sentir, o pensar, o agir interligam-se em complexas redes que geram 'atos' e são resultantes de uma história singular em um contexto que também é singular, naquilo em que é percebido, interpretado e construído pelo próprio sujeito (2001, p. 94).

A proposta interdisciplinar considera que as atividades humanas, dentro de uma instituição, estão relacionadas diretamente com a dimensão humana. Propõe um ressignificar na concepção sobre o trabalho docente, de modo que ultrapasse o modelo tecnicista, apoiado em paradigmas positivistas de ciência. A interdisciplinaridade se apresenta como complementaridade epistemológica na consecução e compreensão das mudanças e transformações por que passam as sociedades contemporâneas.

Para efetivação do trabalho interdisciplinar, a realidade deve ser observada e analisada pela utilização da metáfora do holograma. Conforme Bueno (2001), essa metáfora permite ao homem sentir-se à vontade com as contradições e paradoxos existentes nas relações humanas contemporâneas. Holograficamente, é possível ser flexível e especializado, central e periférico, desengajado e comprometido. 
Morin (2005) lembra que o princípio hologramático considera que a parte está no todo, mas também o todo está na parte. Essa ideia ultrapassa o reducionismo, que só vê as partes, e o holismo, que só vê o todo. Assim, a interdisciplinaridade, implícita na reflexão fenomenológica e apresentada no pensar complexo, contribuirá para ultrapassar a simples integração dos muitos elementos do conhecimento. Para tanto, uma verdadeira aproximação interliga as partes ao todo e o todo às partes, numa rede de tessituras criativas e significativas, para produção de novos conhecimentos, capazes de ver e considerar a essência e não a aparência, redimensionado o todo e não apenas um aspecto do fenômeno.

A proposta interdisciplinar compreende que as atividades humanas, ligadas à produção de conhecimentos, estão relacionadas diretamente com a dimensão humana e sua subjetividade. A interdisciplinaridade é, pois, uma atividade que se apresenta como complementaridade epistemológica da pesquisa e para a compreensão das transformações que passam as sociedades contemporâneas.

A transdisciplinaridade, por sua vez, é considerada por Morin (2005) como princípio metodológico que nos ajuda a avançar para além do conhecimento disciplinar, pluridisciplinar e interdisciplinar, sem desmerecer a importância e utilidade dos mesmos. Mas, entendendo que eles não são suficientes para busca da compreensão da realidade em sua totalidade complexa, é preciso avançar, ir além, inovar e recriar o que já está estabelecido por meio da transdisciplinaridade. Assim, poderemos lançar pontes para religar as partes ao todo e unir as diferenças, para elaboração de um conhecimento mais profundo, abrangente e interativo. Segundo Paul:

"A transdisciplinaridade é compreendida como método de resolução de situações vistas como complexas e paradoxais, implicando a consideração das distintas e da relação entre os níveis fenomenológicos, epistemológicos e lógicos que descrevem o sujeito. Cada um desses níveis inscreve-se em um processo 'antropoformador' e ontogenético que articula subjetividade e objetividade, constituindo a tessitura dos fenômenos humanos" (2013, p. 83)

Esse conceito ontológico de natureza fenomenológica vai nos mostrar a necessidade de compreender as múltiplas dimensões do mundo enquanto realidade complexa e lócus do vir a ser de todos nós. Nesse sentido, a transdisciplinaridade é fundamental para perceber o que, de acordo com Moraes (2014), articula, liga e interliga os diferentes níveis de realidade e, portanto, constitui a complexidade.

Ao mesmo tempo, nos revela a ruptura da lógica clássica e a emergência de uma terceira possibilidade não prevista, o que caracteriza o estar aberto a novas visões possíveis. Essa percepção e vivência, mediante as quais se articula e se percebe a ligação existencial de dois ou mais níveis de realidade, acontece a partir da consciência de cada sujeito, de sua capacidade de percepção da tessitura que existe entre esses níveis e da convergência dos diferentes processos interagindo.

\section{Educação humana, formação integral e sistêmica}

A educação deve ser implementada como possibilidade de reforçar a dimensão humana pelo contato com as diversas formas de pensar, sentir, aprender e praticar o conhecimento, que não é veredito, não está fechado para contribuir, de forma valiosa e rigorosa, com o bem-estar da humanidade. Para isso, precisamos de um docente que compreenda o ser humano por completo, deixando liberar todas as suas capacidades corporais, relacionais, afetivas, intelectuais e espirituais.

Torre (2009) nos remete ao perfil criativo necessário à educação humana, pois propicia a dimensão sensível, articulada aos interesses e necessidades do ser, nas dimensões sociais, afetivas e espirituais, para uma consciência solidária, ética e global. A fenomenologia e a complexidade nos remetem a reflexões sobre a educação capaz de 
propiciar um ensinar a caminhar com autonomia, para emancipação intelectual. Para que tenhamos êxito, será preciso que o mestre reconheça que ele necessita aprender mais que o estudante, justamente porque deve aprender a deixar aprender.

Para educação na dimensão humana, o conhecimento não pode ser fragmentado e nem dissociado dos aspectos físico-material, mental-emocional, intelectual-ético e psíquico-espiritual, para que o desenvolvimento integral das pessoas seja garantido. Reiteramos que educar não é só formar indivíduos tecnicamente capazes, mas é descortinar horizontes. É necessário compreender que a educação é um processo interminável, pois aprendemos desde que nascemos, e a vida nos oferece, sistematicamente, novas e significativas dimensões em relação à realidade.

Necessitamos formar professores que, além de criticar o ensino deficiente, lutem por soluções. Esse é o docente que recorre ao ideal de sua profissão que é desvendar horizontes para a conquista de uma sociedade mais humana. Em uma sociedade humanizada, o cumprimento de normas e regra, não poderá ser empecilho para o desenvolvimento de uma prática pedagógica que contribua para a dignificação dos educandos (Bueno, 2001).

O docente com uma formação complexa e fenomenológica busca uma relação de respeito ao ser estudante; realiza seu trabalho com autoridade, sem ser autoritário. Propicia um ambiente de resiliência ao aluno, de liderança compartilhada e, com rigor, amor e esperança, realiza seu trabalho para a promoção pessoal e social do educando. $\mathrm{O}$ professor, nesta perspectiva, é, pois, aquele que luta para recuperar o espaço ético em que a prática pedagógica deve se desenvolver, sabendo que é sujeito autônomo nesse processo de busca, além de protagonista de mudanças.

Compreendemos, assim como Moraes (2012), que todo processo formativo implica uma dinâmica de natureza auto/hetero/ecoformadora aberta, fundada na solidariedade, no questionamento constante e nas reflexões sobre as ações desenvolvidas. Essa capacidade de questionar traz consigo a complexidade, a incerteza, a perplexidade, a emergência e a mudança, dimensões que requerem do profissional docente um compromisso maior, bem como uma responsabilidade mais acentuada, como decorrências de sua consciência transdisciplinar e fenomenológica.

Não pretendemos propor métodos ou modos de fazer prontos e acabados. Mas pensar as perspectivas apresentadas como possibilidades para assumir a abertura e a flexibilidade, compatíveis com as singularidades dos contextos e sujeitos, num desafio ao modo de pensar prescritivo, ainda existente na educação contemporânea e na formação docente. É urgente repensar toda prática humana, no resgate desse mesmo humano, que há muito estamos perdendo. É preciso recuperar a dimensão ética da ação humana e a sensibilidade que há em cada um de nós, para que todas as nossas ações e atitudes sejam revestidas de respeito e amor a nós, aos outros e ao mundo. Dessa forma, estaremos contribuindo para a promoção da vida humana.

\section{Conclusões}

Para repensar a formação docente no enfoque humano, consciente e criativo é preciso lembrar as palavras de Toynbee:

A dignidade humana não pode ser obtida no campo da tecnologia onde os homens são tão hábeis. Ela só pode ser conquistada no campo da ética e o progresso ético é medido pelo grau em que nossos atos são pautados pela compaixão e pelo amor e não pela cobiça e agressividade (apud Moraes, 2003, p. 20).

É necessária, portanto, uma transformação da educação em convergência com as necessidades humanas, para o estímulo das relações de convivência solidária. Esses 
aspectos são fundamentais em projetos institucionais educativos preocupados em formar de modo integral a pessoa, considerando, nesse processo, tanto a profissão como a vida nas múltiplas interações.

A educação e, especificamente, as propostas de formação docente, têm um papel importante a cumprir para efetivar uma formação humana integral. Elas precisam estimular que o docente associe a teoria à prática para resolver problemas, utilizando suas potencialidades, com criatividade e ousadia, para que as mudanças necessárias, no âmbito do Brasil e do exterior, resultem em ganhos sociais e planetários.

Esses referenciais coadunam para uma educação humana, emancipadora, integral, intencional e global. Uma educação capaz das aproximações de saberes em rede de interações, para articular teoria e prática, sujeito e objeto, razão e emoção, compreendendo que são inseparáveis, pois são faces de uma mesma moeda, cujo valor é inesgotável, considerando a incompletude humana e a complexidade do mundo.

A opção pela abordagem educacional assentada no paradigma da complexidade e na dimensão fenomenológica exige, pois, de cada um de nós, o comprometimento com o humano e suas dimensões múltiplas, além de uma reflexão sistêmica sobre o mundo, a sociedade e a educação. Nos convida a um questionamento constante de nosso agir e fazer, no sentido de repensar o papel da educação e da formação docente. Trata-se de um caminho reflexivo, indispensável para compreender a relevância do papel do docente que educa para vida, ou seja, que existe como cidadão que colabora na formação de novas gerações comprometidas com uma cidadania que promove o bemestar individual, social e do meio ambiente.

\section{Referências}

Bastos, A. V. B. (2001). Cognição e ação nas organizações. In: E. Davel, E. e S. C. Vergara (Org.) Gestão com pessoas e subjetividade. (pp. 157-169). São Paulo: Atlas.

Brenchetti, R. G. (1999). Modelo Neoliberal e Políticas Educacionais. São Paulo: Cortez.

Bueno, E. R. A. (2001). Fenomenologia e a ressignificação do trabalho docente. (Dissertação de Mestrado). Goiânia: Universidade Federal de Goiás - UFG.

Bueno, E. R. B. (2016). Gestão Educacional Fenomenológica: projeto humano em construção. In: A. J. Peixoto (Org.) Fenomenologia e Formação. (pp. 37-48). Curitiba: CRV.

Bueno, E. R. de A. (2014). Fenomenologia: a volta às coisas mesmas. In: A. J. Peixoto, (Org.). Interações entre Fenomenologia e Educação. (pp. 84-98). Campinas: Editora Alínea.

Fazenda, I. (Org.). (2001). Dicionário em construção: interdisciplinaridade. São Paulo: Cortez, 2001.

Freire, P. (2007). Pedagogia da autonomia: saberes necessários à prática educativa. São Paulo: Paz e Terra.

Heidegger, Martin. (1988). Ser e tempo. Trad. Márcia de Sá Cavalcante. 3ª. ed. Petrópolis: Vozes.

Husserl, E. (1996). A Crise da Humanidade Europeia e a Filosofia. Porto Alegre: EDIPUCRS.

Merleau-Ponty, M. (1999). Fenomenologia da Percepção. São Paulo: Martins Fontes. 
Mészáros, I. (2005). A educação para além do capital. São Paulo: Boitempo.

Moraes, M. C. (2003). Pensamento eco-sistêmico: educação, aprendizagem e cidadania no século XXI. Petrópolis: Vozes.

Moraes, M. C. (Org.) 2014. O pensar complexo na Educação: sustentabilidade, transdisciplinaridade e criatividade. São Paulo: WAK Editora.

Moraes, M. C., e Almeida, M. A. (2012). Os sete saberes necessários a uma educação transformadora. Rio de Janeiro: Wak.

Morin, E. (2000). Complexidade e transdisciplinaridade a reforma da universidade $e$ do ensino fundamental. Natal: EdufRN.

Morin, E. (2001). A religação dos saberes: o desafio do século XXI. Tradução e notas Flávia Nascimento. Rio de Janeiro: Bertrand.

Morin, E. (2005). Introdução ao pensamento complexo. $3^{\mathrm{a}}$. ed. Tradução Eliane Lisboa. Porto Alegre: Sulinas.

Morin, E. (2010). Os sete saberes necessários à educação do futuro. São Paulo: Cortez.

Nóvoa, A. (199). Os Professores na Virada do Milênio: do excesso dos discursos à pobreza das práticas. Educação e Pesquisa, 25 (1), 11-20, jan./jun.

Paul, P. (2013). Saúde e transdisciplinaridade. São Paulo: EDUSP.

Pineau, G. (2004). Temporalidades na formação: rumo a novos sincronizadores. São Paulo: Triom.

Pinto, A. M. R. (1992). Pessoas inteligentes trabalhando com máquinas ou máquinas inteligentes substituindo o trabalho humano. In: Vários Autores (Org.). Trabalho e Educação. (pp. 21-29). Campinas: Papirus.

Pukall, J. P., Silva, V. L. S. E Zwierewicz, M. (2017). Ecoformação na educação básica: uma experiência em formação de professores, Professare, 6 (4), no prelo.

Rodrigues, C. G. e Schwantz, J. W. (2016). Buracos Negros na Formação Inicial de Professores de Matemática. Bolema. 30 (56), 939-953.

Santana, P. E. A. (2009). Breve análise sobre as exigências neoliberais na formação docente. In: Atas do IX Congresso Nacional de Educação - Educere, 630-642. Curitiba: PURCR. Recuperado de http://www.pucpr.br/eventos/educere/educere2009/anais/pdf/3342_1494.pdf, em 20 de março de 2016.

Santos, A., Suanno, J. H.; Suanno, M. V. R. (Orgs) (2013). Didática e Formação de Professores: complexidade e transdisciplinaridade. Porto Alegre: Editora Sulina.

Savater, Fernando F. (2000). O Valor de Educar. Tradução Monica Stahel. São Paulo: Martins Pontes.

Suanno, J. H. (2013). Adversidade, resiliência e criatividade: uma articulação oportuna? In: M. V. R. Suanno, M. G. Diettrich e M. A. M. Pujol (Orgs.) Resiliência, criatividade e inovação: potencialidades transdisciplinares na educação. (pp. 3142). Goiânia: UEG/Ed. América.

Suanno, J. H.; Suanno, M. V. R.; Pinho, M. J. (Orgs) (2014). Formação de professores e interdisciplinaridade: diálogo investigativo em construção. Goiânia: América. 
Torre, S. (2009). Uma escola para o século XXI: escolas criativas e resiliência na educação. Florianópolis: Insular.

Zwierewicz, M. (2013). Apresentação. In: M. Zwierewicz (Org.) Criatividade e inovação no Ensino Superior: experiências latino-americanas e europeias em foco. (pp. 9-16). Blumenau: Nova Letra.

Data de recebimento: 03/02/2017

Data da revisão: $30 / 05 / 2017$

Data do aceite: 19/06/2017 
Bueno, E. R. A. e Suanno, J. H. 